\title{
CARDIAC PRECONDITIONING WITH CALCIUM: CLINICALLY ACCESSIBLE MYOCARDIAL PROTECTION
}

Daniel R. Meldrum, MD

Joseph C. Cleveland, Jr., MD

Brett C. Sheridan, MD

Robert T. Rowland, MD

Anirban Banerjee, $\mathrm{PhD}$

Alden H. Harken, MD
Cardiac preconditioning is mediated by protein kinase $\mathrm{C}$. Although endogenous calcium is a potent stimulus of protein kinase $C$, it remains unknown whether preischemic administration of exogenous calcium can induce protein kinase $\mathrm{C}$-mediated myocardial protection against ischemia-reperfusion injury. To study this, calcium chloride was administered retrogradely through the aorta at a rate $5 \mathrm{nmol} / \mathrm{min}$ for 2 minutes to isolated perfused rat hearts 10 minutes before a 20 -minute ischemia and 40 -minute reperfusion insult. Calcium-mediated cardioadaptation was then linked to protein kinase $\mathbf{C}$ by means of the protein kinase $C$ inhibitor chelerythrine $\left(20 \mu \mathrm{mol} \cdot \mathrm{L}^{-1} \cdot 2\right.$ $\min ^{-1}$ ). To determine whether exogenous calcium administration induces protein kinase $\mathbf{C}$ translocation and activation, immunohistochemical staining for the calcium-dependent protein kinase $\mathrm{C}$ isoform $\alpha$ was performed on adjacent $5 \mu \mathrm{m}$ myocardial sections with and without calcium chloride treatment. Results indicated that preischemic calcium chloride administration improved myocardial functional recovery, as determined by enhanced developed pressure, improved coronary flow, reduced end-diastolic pressure, and decreased creatine kinase leakage during reperfusion. Beneficial effects of calcium chloride were eliminated by concurrent protein kinase $\mathrm{C}$ inhibition. Immunohistochemical staining for the $\alpha$ isoform of protein kinase $C$ demonstrated that calcium chloride induces translocation of this isoform from the cytoplasm to the sarcolemma, indicating that exogenous calcium administration activates this isoform. These results suggest that calcium chloride, a safe and routinely administered agent, can induce protein kinase $\mathrm{C}$-mediated cardiac preconditioning. Calcium-induced cardioadaptation to ischemiareperfusion injury may be promising as a clinically feasible therapy before planned ischemic events such as cardiac allograft preservation and elective cardiac operations. (J Thorac Cardiovasc Surg 1996;112:778-86)
C ardiac preconditioning, first termed "ischemic preconditioning," confers myocardial protection against ischemia-reperfusion injury. ${ }^{1-11}$ Several apparently disparate stimuli, including adenosine, nor-

From the Division of Cardiothoracic Surgery, Department of Surgery, University of Colorado Health Sciences Center, Denver, Colo.

Supported by National Institutes of Health grants HL-43696, HL-44186, and GM-08315. D.R.M. is a recipient of the National Institutes of Health National Research Service Award.

Received for publication Nov. 1, 1995; revisions requested Dec. 6 , 1995; revisions received Jan. 5, 1996; accepted for publication Feb. 13, 1996.

Address for reprints: Daniel R. Meldrum, MD, Department of Surgery, University of Colorado Health Sciences Center, 4200 E. Ninth Ave., C-320, Denver, CO 80262.

Copyright $(\mathcal{C} 1996$ by Mosby-Year Book, Inc.

0022-5223/96\$5.00+0 $\mathbf{1 2 / 1 / 7 2 6 6 2}$ epinephrine, and bradykinin, simulate the protective effects of ischemic preconditioning. ${ }^{1-4,7,10}$ Although cardiac preconditioning with either ischemia or pharmacologic agents is possible in animal models, clinical application has been limited for two reasons: (1) ischemic preconditioning stimuli are clinically unappealing, and (2) cardiac preconditioning requires planned ischemic events. Elective cardiac operations and heart transplantation may represent the extent of cardiac preconditioning's clinical application.

The protective effects of different cardiac preconditioning stimuli appear to rely on protein kinase $\mathrm{C}$ (PKC) as a common intracellular effector. ${ }^{3,4,11-15}$ Indeed, we ${ }^{3}$ and others ${ }^{11,12}$ have directly activated PKC with phorbol esters and diacylglycerol, simulating the protection afforded by ischemic preconditioning. ${ }^{3,11,12}$ Calcium is an important endogenous 
activation stimulus of calcium-dependent PKC isoforms (cPKC). ${ }^{16}$ It is unknown whether the administration of exogenous calcium chloride $\left(\mathrm{CaCl}_{2}\right)$, which is both relatively safe and routinely administered clinically, can induce PKC-mediated myocardial functional protection. To study this, exogenous $\mathrm{CaCl}_{2}$ was administered as a preconditioning stimulus before ischemia-reperfusion to determine the following: (1) whether preischemic $\mathrm{CaCl}_{2}$ administration can induce endogenous myocardial functional protection, (2) whether $\mathrm{CaCl}_{2}$ reduces myocellular damage (as marked by creatine kinase [CK] leakage), (3) whether $\mathrm{CaCl}_{2}$ results in translocation and activation of the $\alpha \mathrm{cPKC}$ isoform $(\alpha \mathrm{PKC})$, and (4) whether $\mathrm{CaCl}_{2}$-induced myocardial protection is mediated by PKC.

\section{Materials and methods}

Materials. Male Sprague-Dawley rats (weight 325 to $350 \mathrm{gm}$; Sasco, Omaha, Neb.) were fed a standard diet and acclimated in a quiet quarantine room for 2 weeks before the experiments. The animal protocol was reviewed and approved by the Animal Care and Research Committee of the University of Colorado Health Sciences Center. All animals received humane care in compliance with the "Guide for the Care and Use of Laboratory Animals" prepared by the National Institute of Laboratory Animal Resources and published by the National Institutes of Health (NIH publication No. 86-23, revised 1985). The PKC inhibitor chelerythrine was obtained from L C Laboratories (Woburn, Mass.). Antibody to $\alpha \mathrm{PKC}$ was obtained from Santa Cruz Biotechnology, Inc. (Santa Cruz, Calif.). All other chemicals and reagents were obtained from Sigma Chemical Co. (St. Louis, Mo.).

Experimental design and groups. Each ischemia-reperfusion experiment totaled 80 minutes, beginning with a mandatory equilibration period. Stability control hearts (with and without $0.25 \mathrm{mmol} / \mathrm{L} \mathrm{CaCl}_{2}$ and $20 \mu \mathrm{mol} / \mathrm{L}$ chelerythrine treatment) underwent 80 minutes of oxygenated perfusion without any ischemia to ensure preparation stability. Injury control hearts were perfused for 8 minutes (equilibration) and then received 2-minute infusions of each respective vehicle, followed by a 10 -minute washout period, and a standard ischemia-reperfusion insult ( 20 minutes of $37^{\circ} \mathrm{C}$ global ischemia and 40 minutes of reperfusion). $\mathrm{CaCl}_{2}$-treated hearts received 8 minutes of perfusion followed by a 2-minute retrograde aortic infusion of $\mathrm{CaCl}_{2}$ at $5 \mathrm{nmol} / \mathrm{min}$ for 2 minutes (based on a $20 \mathrm{ml} / \mathrm{min}$ coronary flow $[\mathrm{CF}]$ rate). This was followed by a 10-minute washout period of standard perfusion. The $\mathrm{CaCl}_{2}$ dose was based on dose-response curves generated in our laboratory, which demonstrated that this dose provided optimal protection compared with both higher and lower doses. To determine whether the observed protective effects of $\mathrm{CaCl}_{2}$ were mediated by $\mathrm{PKC}$, the PKC inhibitor chelerythrine was administered with and without $\mathrm{CaCl}_{2}$ after equilibration, 10 minutes before the standard ischemia-reperfusion protocol. All drug solu- tions were prepared in deionized water and infused through a port above the aortic root at $0.1 \mathrm{ml} / \mathrm{min}$ (not recirculated). Hemodynamic parameters were continuously recorded before, during, and after infusion.

Ischemia-reperfusion of the isolated rat heart: developed pressure (DP), end-diastolic pressure (EDP), CF, and heart rate measurements. The isolated, crystalloidperfused rat heart model described elsewhere was used. $^{2-4,17,18}$ In brief, after anesthesia and heparinization $(60 \mathrm{mg} / \mathrm{kg}$ intraperitoneal sodium pentobarbital and 500 units intraperitoneal heparin sodium) hearts were excised into $4^{\circ} \mathrm{C}$ Krebs-Henseleit solution and perfused with oxygenated buffer within 45 seconds. Hearts were retrogradely perfused in the isolated, isovolumetric Langendorff mode $(70 \mathrm{~mm} \mathrm{Hg})$ with modified Krebs-Henseleit solution $(5.5 \mathrm{mmol} / \mathrm{L}$ glucose, $1.2 \mathrm{mmol} / \mathrm{L}$ calcium ion $\left[\mathrm{Ca}^{2+}\right], 4.7 \mathrm{mmol} / \mathrm{L}$ potassium chloride, and $25.0 \mathrm{mmol} / \mathrm{L}$ sodium bicarbonate) and saturated with $92.5 \%$ oxygen and $7.5 \%$ carbon dioxide atmosphere to achieve an oxygen tension of 440 to $460 \mathrm{~mm} \mathrm{Hg}$, a carbon dioxide tension of 39 to $41 \mathrm{~mm} \mathrm{Hg}$, and a pH of 7.39 to 7.41 (ABL-4 blood gas analyzer; Radiometer Medical A/S, Copenhagen, Denmark). Pulmonary arteriotomy and left atrial resection were performed before insertion of a water-filled latex balloon through the left atrium into the left ventricle. The balloon was then adjusted to a left ventricular EDP of $6 \mathrm{~mm} \mathrm{Hg}$ during the initial equilibration. This preload volume was held constant during the entire experiment to allow continuous recording of the ventricular pressure during ischemia-reperfusion. Pacing wires were fixed to the right atrium and pulmonary outflow tract and hearts were paced at approximately $6 \mathrm{~Hz}$ ( 355 beats $/ \mathrm{min}$ ) for 1 minute to ensure a standardized heart rate during the time points at which DP was measured. During the remainder of the experiments, the pacer was off. A unipolar electrocardiogram was obtained through a lead placed on either the right or left ventricular free wall to allow continuous recording of an electrocardiographic signal.

Measured indexes of myocardial function were left ventricular $\mathrm{DP}, \mathrm{EDP}, \mathrm{CF}$, and native heart rate. Data were continuously recorded with a computerized MacLab 8 preamplifier/digitizer (AD Instruments Inc., Milford, Mass.) and an Apple Quadra 800 computer Inc., Cupertino, Calif.). The electrocardiographic signal was amplified with a DP-301 differential amplifier (Warner Instrument Corp., Hamden, Colo.) and digitized at $400 \mathrm{~Hz}$ on the MacLab 8 preamplifier/digitizer. Paced hearts that did not produce $105 \pm 25 \mathrm{~mm} \mathrm{Hg} \mathrm{DP}$ at $6 \mathrm{~mm} \mathrm{Hg} \mathrm{EDP} \mathrm{were}$ discarded. A three-way stopcock above the aortic root was used to create global ischemia, during which time the heart was placed in a $37^{\circ} \mathrm{C}$ degassed organ bath. CF was measured in graduated cylinders at the end of equilibration, immediately after drug infusion, and at the end of reperfusion. At 10, 20, 30, and 40 minutes of reperfusion, $1 \mathrm{ml}$ coronary effluent was collected and frozen at $-70^{\circ} \mathrm{C}$. Coronary effluent $\mathrm{CK}$ activity was determined within 2 weeks.

Coronary effluent CK activity. Coronary effluent $(1 \mathrm{ml})$ was collected at 10,20,30, and 40 minutes of reperfusion and then frozen at $-70^{\circ} \mathrm{C}$ until assay. All assays were performed within 2 weeks of effluent collection. The assay 
was performed with Sigma diagnostic kit no. 47-UV on an automated spectrophotometer (Centrifichem 500 discrete autoanalyzer; Union Carbide Chemicals \& Plastics Co. Inc., Bound Brook, N.J.) in cuvettes maintained at $37^{\circ}$ C. Samples and reagents were maintained at $4^{\circ} \mathrm{C}$ before assay. Solutions were prepared in distilled, deionized water. Results are presented as CK activity in units per liter.

Subcellular localization of $\alpha \mathrm{PKC}$. Myocardial subcellular localization of the $\alpha \mathrm{PKC}$ was performed with immunofluorescence staining. These hearts were obtained immediately after 2 -minute $\mathrm{CaCl}_{2}$ infusion $(0.25 \mathrm{mmol} / \mathrm{L})$ in $\mathrm{CaCl}_{2}$-treated hearts and after 10 -minute equilibration in control hearts. Ventricular tissue was excised from isolated beating hearts, blotted, embedded in tissue-freezing medium, rapidly frozen in dry ice-cooled 2-methylbutane, and stored at $-70^{\circ} \mathrm{C}$. Transverse $5 \mu \mathrm{m}$ cryosections were prepared with a cryostat (2800 Frigocut E; Reichert-Jung, Germany) and collected on slides coated with poly-Llysine. All sections were fixed for 10 minutes in a $70 \%$ acetone $-30 \%$ methanol mixture at $-20^{\circ} \mathrm{C}$. Normal goat serum $(5 \%$ in phosphate-buffered saline solution [PBS] and $5 \%$ normal sheep serum) was applied as a blocking agent and washed three times in PBS for 3 minutes. Sections from the experimental groups were then incubated for 1 hour with diluted primary antibody (rabbit polyclonal antibody against $\alpha \mathrm{PKC}$ ) at room temperature with mouse antisarcomeric $\alpha$-actin antibody. For all groups, individual PKC isoform staining was performed on adjacent sections. After the sections were washed three times with PBS for 3 minutes, they were incubated with Cy-3 conjugated goat antirabbit IgG for 45 minutes. During this step, sections were also exposed to antisarcomeric $\alpha$-actin antibody coincubated with fluorescein isothiocyanate-conjugated sheep antimouse immunoglobulin $G$ antibody. Sections were then washed three times with PBS for 3 minutes. Slides were mounted with a glycerol-based antiquenching agent ( $O$-phenylene diamine-D:HCl) and stored at $4^{\circ} \mathrm{C}$. To test for nonspecific fluorescence, adjacent sections of each experimental group were incubated with nonimmune purified rabbit immunoglobulin $G$ instead of primary antibodies. Sections were viewed and photographed with a microscope equipped with fluorescence optics (Axioskop with MC-100 camera; Carl Zeiss, Oberkochen, Germany). Multiple sections per heart were examined. Three different hearts were examined per group. Representative sections are presented.

Presentation of data and statistical analysis. All reported values are mean ( \pm standard error of the mean, $n=6$ to 8 per group). Differences at the $95 \%$ confidence level were considered significant. Functional recoveries-DP (in millimeters of mercury), left ventricular EDP (in millimeters of mercury), CF (in milliliters per minute), heart rate (in beats per minute), and CK activity (in units per liter)-were compared at the corresponding time points between groups with one-way analysis of variance with post hoc Bonferroni-Dunn test (StatView 4.0; Abacus Concepts, Inc., Berkeley, Calif.).

\section{Results}

Twenty minutes of normothermic $\left(37^{\circ} \mathrm{C}\right)$ global ischemia was chosen as the ischemia-reperfusion insult because this reproducibly establishes a $50 \%$ decrease in functional recovery of untreated hearts. ${ }^{2-4,17-19} \mathrm{Fi}-$ nal function in $\mathrm{CaCl}_{2}$-pretreated hearts was greater than $75 \%$, which provided a dynamic range within which cardiac functional protection could be studied. Stability control hearts for vehicle, $\mathrm{CaCl}_{2}$, and chlerythrine-treated hearts retained more than $95 \%$ of baseline DP, heart rate, and CF.

Effects of $\mathrm{CaCl}_{2}$ pretreatment, with and without concurrent PKC inhibition, on DP. The effect of preischemia $\mathrm{CaCl}_{2}$ on DP after ischemia-reperfusion was explored in a manner similar to that in previous regional and global ischemia isolated rat heart models. ${ }^{2-4,17-19}$ DP did not differ between the groups during equilibration and measured $112 \pm 9$, $113 \pm 7,117 \pm 8$, and $115 \pm 7 \mathrm{~mm} \mathrm{Hg}$ in the control, $\mathrm{CaCl}_{2}, \mathrm{CaCl}_{2}$ plus chelerythrine, and chelerythrine groups, respectively (Fig. 1). After agent or vehicle administration, DP increased transiently in the $\mathrm{CaCl}_{2}$ and the $\mathrm{CaCl}_{2}$ plus chelerythrine groups to $124 \pm 9$ and $125 \pm 8 \mathrm{~mm} \mathrm{Hg}$, respectively. DP did not change after vehicle (control) or chelerythrine administration alone. After washout, DP returned to baseline in all groups. At 40 minutes of reperfusion, DP was increased in the $\mathrm{CaCl}_{2}$ group $89 \pm$ 6.1) with respect to control, $\mathrm{CaCl}_{2}$ plus chelerythrine, and chelerythrine groups, which measured $60.2 \pm 6.8,69 \pm 9$, and $58 \pm 7$, respectively $(p<$ $0.05)$.

Effects of $\mathrm{CaCl}_{2}$ pretreatment, with and without concurrent PKC inhibition, on CF. The effect of preischemia $\mathrm{CaCl}_{2}$ on $\mathrm{CF}$ after ischemia-reperfusion is shown in Fig. 2. During equilibration, CF did not differ among the groups and measured $20 \pm 1.2$, $20.5 \pm 1.6,20.4 \pm 1.5$, and $19.8 \pm 1.4 \mathrm{ml} / \mathrm{min}$ in the control, $\mathrm{CaCl}_{2}, \mathrm{CaCl}_{2}$ plus chelerythrine, and chelerythrine groups, respectively. After agent or vehicle administration, $\mathrm{CF}$ increased transiently in the $\mathrm{CaCl}_{2}$ and the $\mathrm{CaCl}_{2}$ plus chelerythrine groups to $22 \pm 1.4$ and $21.8 \pm 1.4 \mathrm{ml} / \mathrm{min}$, respectively. CF did not change after vehicle (control) or chelerythrine administration alone. After washout, $\mathrm{CF}$ returned to baseline in all groups. At 40 minutes of reperfusion, $\mathrm{CF}$ was increased in the $\mathrm{CaCl}_{2}$ group $(17.5 \pm 1.2$ $\mathrm{ml} / \mathrm{min}$ ) with respect to the control, $\mathrm{CaCl}_{2}$ plus chelerythrine, and chelerythrine groups, which measured $12 \pm 1.8,13 \pm 2$, and $12.5 \pm 1.2 \mathrm{ml} / \mathrm{min}$, respectively $(p<0.05)$.

Effects of $\mathrm{CaCl}_{2}$ pretreatment, with and without concurrent PKC inhibition, on EDP after ischemia and during reperfusion. $\mathrm{CaCl}_{2}$ pretreatment decreased EDP after ischemia-reperfusion from $46 \pm$ 


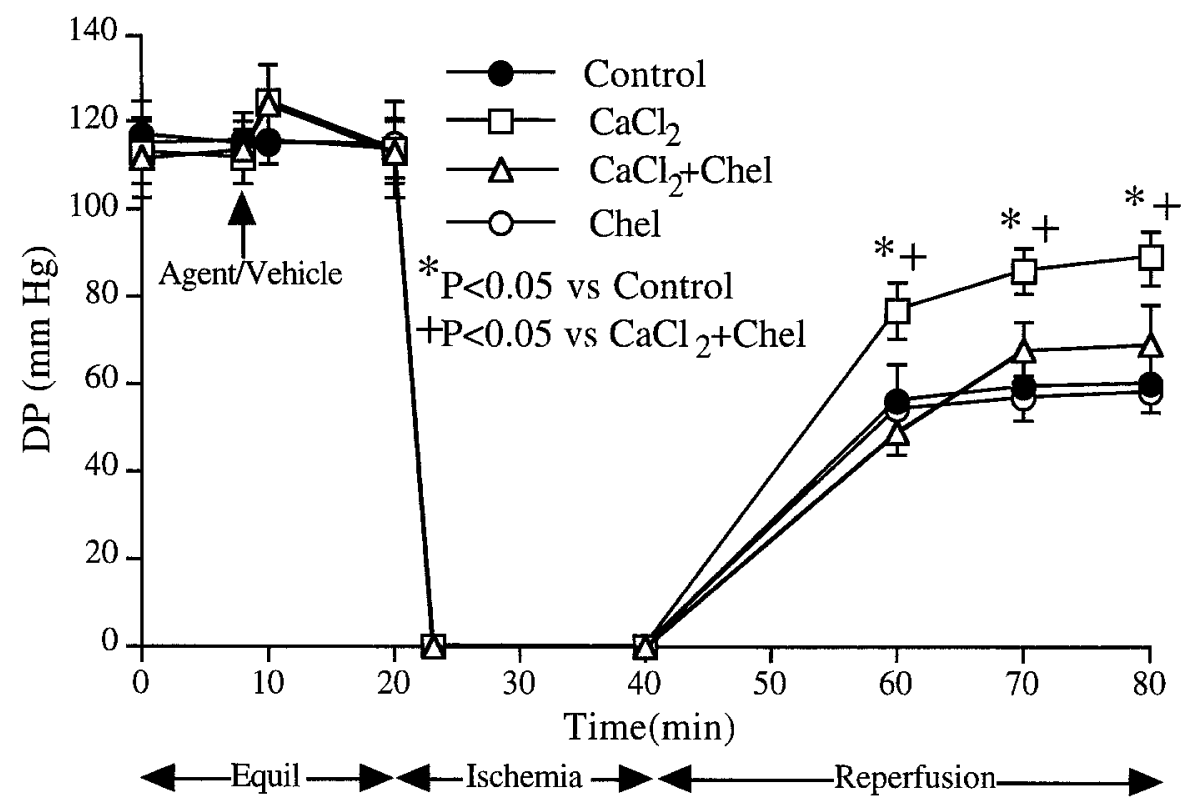

Fig. 1. Effect of preischemic administration of $\mathrm{CaCl}_{2}$, with and without $\mathrm{PKC}$ inhibition, on myocardial DP during ischemia-reperfusion. During equilibration, DP averaged approximately $110 \mathrm{~mm} \mathrm{Hg}$ in all groups. After agent or vehicle administration, there was a transient increase in DP in $\mathrm{CaCl}_{2}$ and $\mathrm{CaCl}_{2}$ plus chelerythrine (Chel) groups; DP rapidly returned to baseline after the 2-minute infusion. During ischemia, DP decreased to $0 \mathrm{~mm} \mathrm{Hg}$ in all groups. During reperfusion, DP recovery of $\mathrm{CaCl}_{2}$-treated group was increased with respect to control, $\mathrm{CaCl}_{2}$ plus chelerythrine, and chelerythrine groups. $n=6$ to 8 per group. Equil, Equilibration.

6 to $29 \pm 4 \mathrm{~mm} \mathrm{Hg}(p<0.05$; Fig. 3). After PKC inhibition with chelerythrine, the EDP of $\mathrm{CaCl}_{2}$ treated hearts was similar to that of ischemiareperfusion control hearts, $43 \pm 3 \mathrm{~mm} \mathrm{Hg}(p<0.05$ vs $\mathrm{CaCl}_{2}$ ). Chelerythrine infusion alone did not result in any additional increase in EDP compared with ischemia-reperfusion alone, $47 \pm 4.3 \mathrm{~mm} \mathrm{Hg}$ $\left(p<0.05\right.$ vs $\left.\mathrm{CaCl}_{2}\right)$.

Effect of $\mathrm{CaCl}_{2}$ pretreatment, with and without concurrent PKC inhibition, on coronary effluent CK activity. CK activities in coronary effluents (CK leakage) were determined at 10,20,30, and 40 minutes of reperfusion and are shown in Fig. 4. At 10 minutes of reperfusion, coronary effluent $\mathrm{CK}$ activities were $58.02 \pm 10.5,38.92 \pm 8.6$, and $56.79 \pm 12.75 \mathrm{U} / \mathrm{L}$ in the control, $\mathrm{CaCl}_{2}$, and $\mathrm{CaCl}_{2}$ plus chelerythrine groups, respectively. At 20 minutes of reperfusion, coronary effluent CK activities were $59.55 \pm 9.74,45.78 \pm 7.45$, and $72.64 \pm 8.6$ $\mathrm{U} / \mathrm{L}$ in the control, $\mathrm{CaCl}_{2}$, and $\mathrm{CaCl}_{2}$ plus chelerythrine groups, respectively $\left(p<0.05 \mathrm{CaCl}_{2}\right.$ vs $\mathrm{CaCl}_{2}$ plus chelerythrine). At 30 minutes of reperfusion, the $\mathrm{CK}$ leakage of the $\mathrm{CaCl}_{2}$-treated group was less than those in both $\mathrm{CaCl}_{2}$ plus chelerythrine and control groups, measuring $29.77 \pm 8.4$ versus 57.87 \pm 11.56 and $67.8 \pm 11.1 \mathrm{U} / \mathrm{L}$, respectively $(p<0.05$ vs control and $\mathrm{CaCl}_{2}$ plus chelerythrine). At 40 minutes of reperfusion, the CK leakage of the $\mathrm{CaCl}_{2}$-treated group was less than those in both $\mathrm{CaCl}_{2}$ plus chelerythrine and control groups, measuring $19.69 \pm 7.4$ versus $52.65 \pm 9.2$ and $54.18 \pm$ $7.6 \mathrm{U} / \mathrm{L}$, respectively ( $p<0.05$ vs control and $\mathrm{CaCl}_{2}$ plus chelerythrine). Chelerythrine treatment alone did not affect CK leakage compared with the control group. At 10, 20, 30, and 40 minutes of reperfusion, the CK leakages in the chelerythrine-treated group measured $62.4 \pm 7.6,56.72 \pm 8.2,54.2 \pm 9.7$, and $47.6 \pm 7.4 \mathrm{U} / \mathrm{L}$, respectively.

Effect of $\mathrm{CaCl}_{2}$ on $\alpha \mathrm{PKC}$ translocation. Translocation of PKC from cytosolic to particulate compartments is commonly used as an index of activation. ${ }^{3,46}$ Indirect immunofluorescent microscopy was used to verify $\mathrm{Ca}^{2+}$-induced activation of the calcium-dependent $\alpha$ PKC. Although this technique primarily provides qualitative data, the use of isoform-specific anti-PKC antibodies allows the assessment of both isoform-selective activation and compartmentalization. Fig. $5(A)$ demonstrates control 


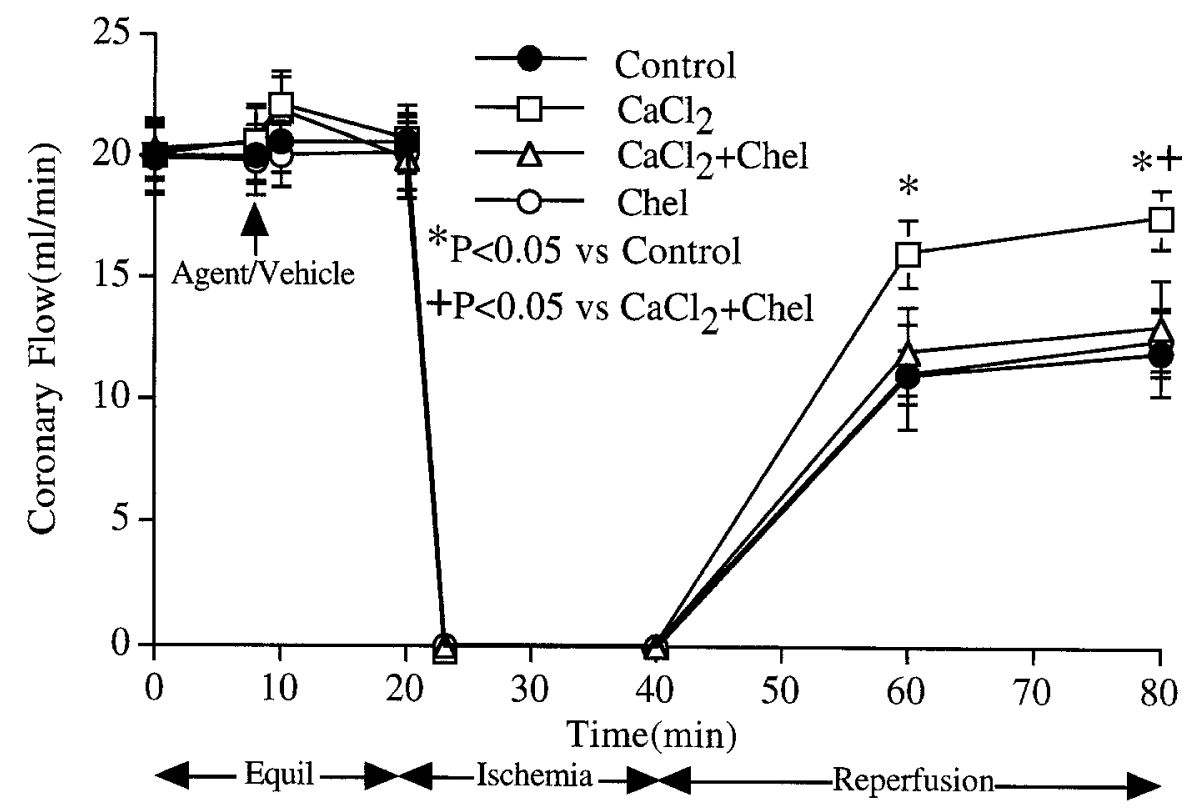

Fig. 2. Effect of preischemic administration of $\mathrm{CaCl}_{2}$, with and without $\mathrm{PKC}$ inhibition, on $\mathrm{CF}$ during ischemia-reperfusion. During equilibration, $\mathrm{CF}$ averaged approximately $20 \mathrm{ml} / \mathrm{min}$ in all groups. After agent or vehicle administration, there was a transient increase in $\mathrm{CF}$ in $\mathrm{CaCl}_{2}$ and $\mathrm{CaCl}_{2}$ plus chelerythrine (Chel) groups; CF rapidly returned to baseline after the 2-minute infusion. During ischemia, $\mathrm{CF}$ decreased to $0 \mathrm{ml} / \mathrm{min}$ in all groups. During reperfusion, $\mathrm{CF}$ recovery of the $\mathrm{CaCl}_{2}$-treated group was increased with respect to control, $\mathrm{CaCl}_{2}$ plus chelerythrine, and chelerythrine groups. $n=6$ to 8 per group. Equil, Equilibration.

heart sections with diffuse cytoplasmic distribution of $\alpha \mathrm{PKC}$; after $\mathrm{CaCl}_{2}$ treatment, however, $\alpha \mathrm{PKC}$ translocates to the sarcolemma (Fig. 5, B). Results represent multiple sections from three different hearts per group.

\section{Discussion}

Ischemic preconditioning has emerged as a means of inducing endogenous myocardial protection after ischemia-reperfusion injury. ${ }^{1-4,9,12-14}$ The protective effects of different cardiac preconditioning stimuli appear to rely on PKC as a common intracellular effector. ${ }^{3,4,11-15} \mathrm{Ca}^{2+}$ is an important endogenous activation stimulus of $\mathrm{cPKC} .{ }^{16}$ Although increased intracellular $\mathrm{Ca}^{2+}$ concentration $\left(\left[\mathrm{Ca}^{2+}\right]_{i}\right)$ represents the final common denominator of cell dysfunction and death after ischemia-reperfusion, ${ }^{8,9,20-29}$ it is possible (although counterintuitive) that a preischemic $\mathrm{Ca}^{2+}$ stimulus might incite endogenous events that culminate in myocardial protection against ischemia-reperfusion. A calcium stress thus may provide cardioprotection, analogous to transient ischemic preconditioning, against sustained ischemia-reperfusion. Steenbergen and coworkers ${ }^{9}$ have demonstrated that ischemic preconditioning limits alterations in various intramyocellular ions after ischemia-reperfusion. Ischemic preconditioning therefore appears to induce, or alternatively to "prime," the cellular machinery required to maintain ion homeostasis during a subsequent ischemic episode. These beneficial effects appear to explain, at least in part, preconditioning's protective effects. Although the intermediaries have yet to be completely elucidated, PKC activation is required for all preconditioning stimuli examined to date., $3,411-14$ Indeed, direct PKC activation with phorbol esters and diacylglycerol results in functional and viability protection after ischemia-reperfusion., 11,12 Although $\left[\mathrm{Ca}^{2+}\right]_{i}$ is an important endogenous activator of PKC, it is unknown whether exogenous $\mathrm{Ca}^{2+}$, a clinically accessible and acceptable stimulus, can activate PKC and thereby induce myocardial functional protection.

Our observations suggest that exogenous $\mathrm{CaCl}_{2}$ administration can induce PKC-mediated myocardial functional protection. Exogenous $\mathrm{CaCl}_{2}$ administration before ischemia-reperfusion improved DP (Fig. 1) and CF (Fig. 2) after ischemia-reperfusion and decreased EDP (Fig. 3) and CK leakage (Fig. 4) after ischemia-reperfusion. Furthermore, PKC inhi- 


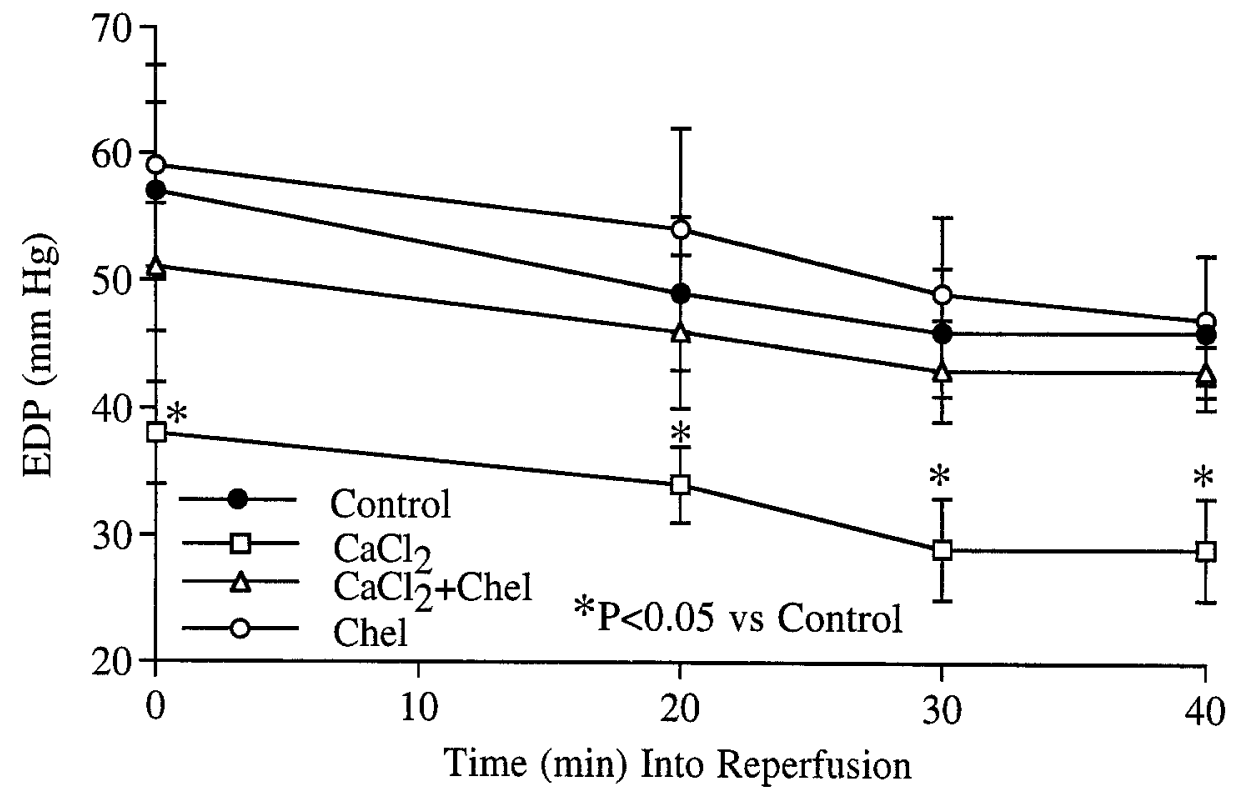

Fig. 3. Effect of preischemic administration of $\mathrm{CaCl}_{2}$, with and without $\mathrm{PKC}$ inhibition, on EDP during reperfusion. After 20 minutes of ischemia, EDP was $57 \mathrm{~mm} \mathrm{Hg}$ in the control group; EDP decreased to approximately $45 \mathrm{~mm} \mathrm{Hg}$ after 40 minutes of reperfusion. $\mathrm{CaCl}_{2}$ pretreatment decreased postischemic EDP to $38 \mathrm{~mm} \mathrm{Hg}$, which decreased further to $29 \mathrm{~mm} \mathrm{Hg}$ after reperfusion. PKC inhibition with chelerythrine (Chel) abolished $\mathrm{CaCl}_{2}$-induced protective effects $\left(\mathrm{CaCl}_{2}+\mathrm{Chel}\right)$. Chelerythrine alone did not result in any additional injury when administered before an indentical ischemia-reperfusion insult. $n=6$ to 8 per group.

bition with chelerythrine abolished these effects (Figs. 1 through 4), thus implicating PKC activation in the mechanism of $\mathrm{CaCl}_{2}$-induced protective effects. Further substantiating the hypothesis that $\mathrm{CaCl}_{2}$ can induce PKC-mediated myocardial functional protection is the observation that $\mathrm{CaCl}_{2}$ results in $\alpha \mathrm{PKC}$ translocation to the sarcolemma (Fig. 5 ). Because $\alpha \mathrm{PKC}$ was the only isoform examined, it is possible that other isoforms inhibited by chelerythrine are involved. The translocation of this isoform may be coincidental, and not responsible for the protection observed. Indeed, different preconditioning stimuli may effect preconditioning through the activation of different isoforms. ${ }^{3,4}$ Nevertheless, $\mathrm{Ca}^{2+}$ preconditioning was indeed prevented by concurrent PKC inhibition. It is of interest that the improved functional recovery observed is derived almost entirely from a reduction in EDP, without appreciable increase in systolic pressure. This suggests that the protective effects may be caused by reduction of irreversible injury, rather than of stunning.

Brief ischemia can itself condition the heart against a more prolonged ischemic insult. ${ }^{1-3,7,9,10,12}$ In an effort to analyze the mechanisms of ischemia-induced functional protection, several investigators established a role for ischemic stress hormones ${ }^{2,4,24,30,31}$ and suggested a role for $\left.\left[\mathrm{Ca}^{2+}\right]_{\mathrm{i}}{ }^{*}\right)$. Ashraf and coworkers ${ }^{20}$ focused on manipulating the extracellular $\mathrm{Ca}^{2+}$ concentration $\left(\left[\mathrm{Ca}^{2+}\right]_{0}\right)$ and report that exposing the heart to a transient depletion and repletion of $\mathrm{Ca}^{2+}$ protects the cell against a subsequent, more severe depletion and repletion of $\mathrm{Ca}^{2+}$ (calcium paradox). Calcium paradox injury indeed approximates the damage inflicted during ischemia-reperfusion injury. It therefore seemed possible that a preischemic $\mathrm{Ca}^{2+}$ stimulus would also provide functional protection against ischemia-reperfusion injury. The mechanisms by which an antecedent stress (ischemia, stress hormones, or elevated $\left[\mathrm{Ca}^{2+}\right]_{i}$ ) results in cardioadaptation to a subsequent insult are only beginning to be elucidated; however, PKC appears to act as a common intracellular effector. ${ }^{3,4,12,14,15}$

The signal transduction cascades of a large number of receptors are linked to PKC. ${ }^{16}$ Consequently, many different stimuli that activate PKC could theoretically lead to cardiac functional protection

\footnotetext{
*References 3, 4, 8, 9, 14, 15, and 20.
} 


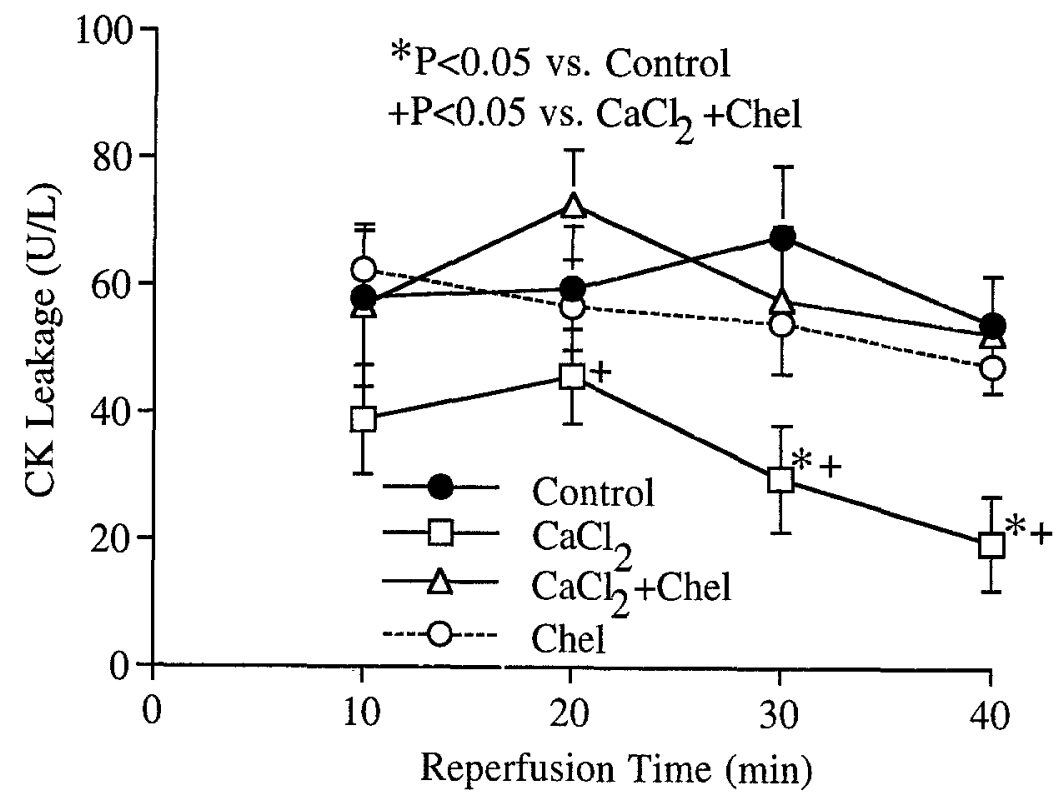

Fig. 4. Effect of preischemic administration of $\mathrm{CaCl}_{2}$, with and without $\mathrm{PKC}$ inhibition, on $\mathrm{CK}$ leakage during reperfusion. At 10, 20, 30, and 40 minutes of reperfusion, $1 \mathrm{ml}$ coronary effluent was collected and assayed for $\mathrm{CK}$ activity in all groups. At 10 minutes of reperfusion, $\mathrm{CK}$ activity in the $\mathrm{CaCl}_{2}$ group averaged approximately $40 \mathrm{U} / \mathrm{L}$, whereas $\mathrm{CK}$ activity in control, $\mathrm{CaCl}_{2}$ plus chelerythrine (Chel), and chelerythrine groups averaged approximately $60 \mathrm{U} / \mathrm{L}$. At 20 minutes of reperfusion, CK activities were similar to those at the 10-minute time point for each group. At 30 and 40 minutes of reperfusion, CK leakage decreased in the $\mathrm{CaCl}_{2}$ group to approximately $20 \mathrm{U} / \mathrm{L}$ by 40 minutes of reperfusion, different from both control and $\mathrm{CaCl}_{2}$ plus chelerythrine groups, which both averaged approximately $55 \mathrm{U} / \mathrm{L}$ at 40 minutes of reperfusion $(p<0.05) . n=6$ to 8 per group.

against ischemia-reperfusion injury. Indeed, transient ischemic, purinergic, and $\alpha_{1}$ adrenergic stimuli, all of which provide myocardial functional protection, appear to act in common through PKC.* PKC regulates intracellular processes both by direct phosphorylation and by initiating the induction of other protein kinase cascades. ${ }^{16}$ Multiple extracellular and intracellular ischemia-responsive stimuli may provide common communication by PKC. Direct PKC activation induces myocardial functional protection, and PKC inhibition can block this protection. ${ }^{3,12,14}$ Endogenous $\left[\mathrm{Ca}^{2+}\right]_{\mathrm{i}}$ is an important activator of PKC, ${ }^{16}$ and elevation of $\left[\mathrm{Ca}^{2+}\right]_{i}$ is also coincident with the action of these ischemic stress stimuli ${ }^{32}$; however, it is unknown whether exogenous $\mathrm{Ca}^{2+}$ administration can activate PKC and thereby induce myocardial functional protection similar to that observed after ischemic preconditioning. Our data suggest that preischemic $\mathrm{CaCl}_{2}$ administration can induce functional protection after ischemia-reperfu-

${ }^{*}$ References $1,3,4,7,12,15$, and 30 . sion and limit myocellular CK leakage by means of a PKC-dependent mechanism.

The exact mechanism by which PKC provides myocardial functional protection is unknown. Because $\mathrm{PKC}$ translocation and activation appear to be central to the functional protection afforded by several different stimuli, it is possible that PKC translocation to various intracellular sites regulates upward the cellular machinery required to adapt to the ensuing ischemia-reperfusion insult. For example, translocation of PKC to the sarcolemma may signify the priming of cellular machinery at this location; phosphorylation and activation of the sodium ion-hydrogen ion exchanger or sodium ion$\mathrm{Ca}^{2+}$ exchanger may prepare the heart to better regulate ion gradients after ischemia-reperfusion. Similarly, sarcoendoplasmic reticulum $\mathrm{Ca}^{2+}$ adenosine triphosphatase activity may be upregulated, allowing the heart to adapt to the subsequent $\mathrm{Ca}^{2+}$ load associated with ischemia-reperfusion injury. This, however, remains to be determined. Indeed, precond ming's link with PKC may only be an 

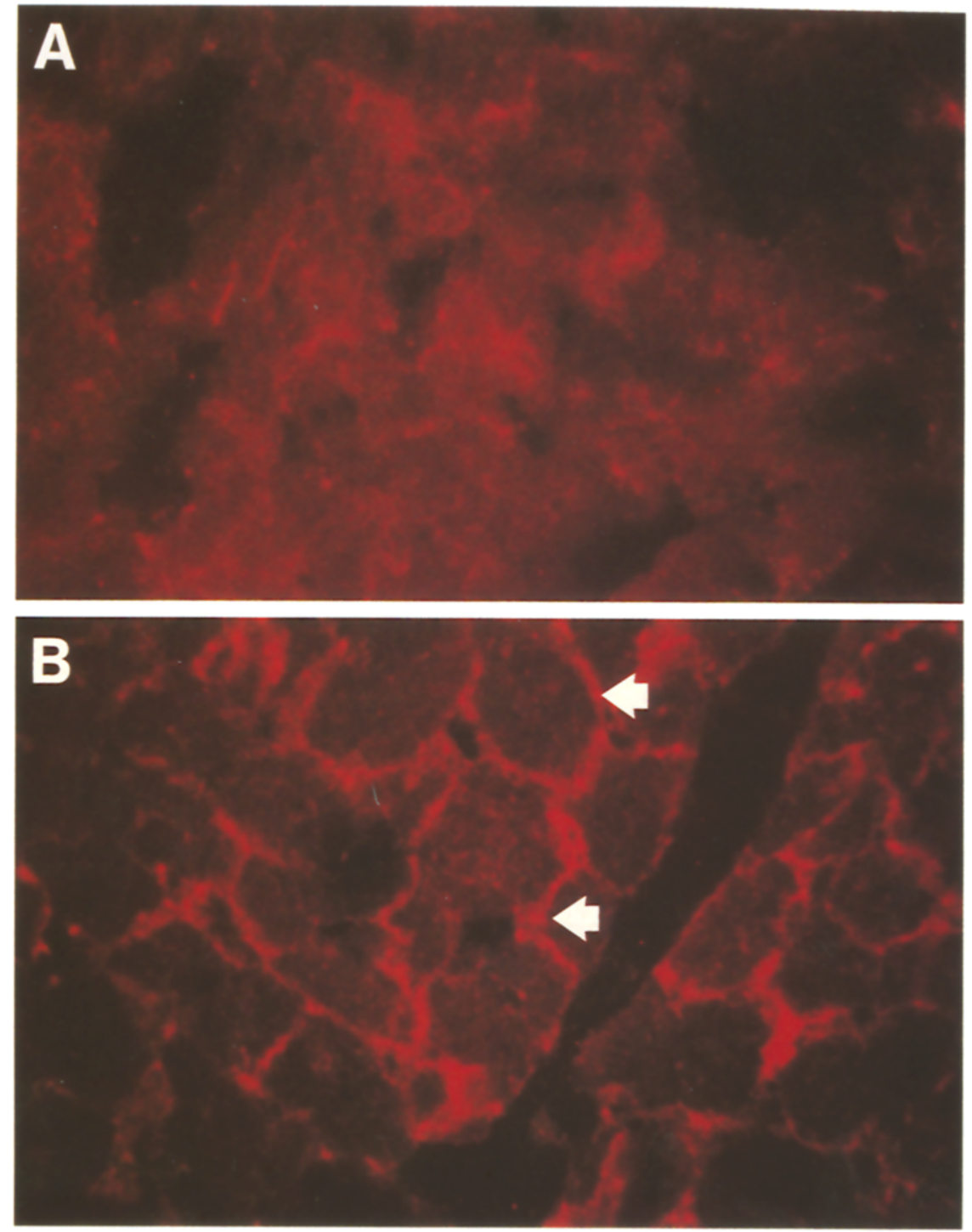

Fig. 5. Immunohistofluorescence images of $\mathrm{PKC}$ translocation after $\mathrm{CaCl}_{2}$ treatment; transverse $5 \mu \mathrm{m}$ cryosections of rat heart incubated with rabbit polyclonal antibody against $\alpha \mathrm{PKC}$. $\mathbf{A}$, Control heart incubated with rabbit polyclonal antibody against $\alpha \mathrm{PKC}$ demonstrates diffuse cytoplasmic staining (original magnification $\times 63$ ). $\mathrm{B}, \mathrm{CaCl}_{2}$-treated heart incubated with rabbit polyclonal antibody against $\alpha \mathrm{PKC}$ demonstrates translocation of this isoform to the sarcolemma (arrows) from the cytoplasm, suggesting that exogenous $\mathrm{CaCl}_{2}$ administration activates $\alpha \mathrm{PKC}$ (original magnification $\times 63$ ).

association. Although PKC may be operative in some forms of preconditioning, other kinases may be operative after other preconditioning stimuli. It is therefore possible according to the work of Asimakis and Conti, ${ }^{31}$ that $\mathrm{Ca}^{2+}$ preconditioning is independent of PKC. These authors reported that dobutamine, which increases $\left[\mathrm{Ca}^{2+}\right]_{i}$ but is not known to activate PKC, also produced functional protection in isolated rat hearts. Furthermore, the mechanism by which exoge- nous $\mathrm{Ca}^{2+}$ activates $\mathrm{PKC}$ remains unknown. It is possible that increasing $\left[\mathrm{Ca}^{2+}\right]_{0}$ increases $\left[\mathrm{Ca}^{2+}\right]_{\mathrm{i}}$ by either calcium-induced-calcium release, voltage-operated channels, or both, and that this increase in $\left[\mathrm{Ca}^{2+}\right]_{i}$ is sufficient stimulus to activate PKC.

The ultimate benefit of preischemic induction of endogenous functional protection relates to its clinical applicability. Transient ischemia, which is a potent protective stimulus in animals, is less appeal- 
ing clinically. Because $\mathrm{CaCl}_{2}$ is both clinically accessible and acceptable, stimulating PKC-mediated myocardial functional protection with preischemic $\mathrm{CaCl}_{2}$ infusion may even provide a means of enhancing cardiac function after transplantation and bypass operations. It must be emphasized, however, that these studies were performed with normal rat hearts. Both the salutary and the deleterious effects of $\mathrm{Ca}^{2+}$ preconditioning of diseased human ventricles remain to be determined.

We thank Drs. David A. Fullerton, James M. Brown, Robert C. McIntyre, Jr., and Xianzhong Meng for their insightful criticisms and suggestions; Dr. Daniel Chan for use of the fluorescent microscope; and Mr. James Walther for suggestions and expert technical assistance.

\section{REFERENCES}

1. Murray C, Jennings R, Reimer K. Preconditioning with ischemia: a delay of lethal cell injury in ischemic myocardium. Circulation 1986;74:1124-36.

2. Banerjee A, Locke-Winter C, Rogers KB, Mitchell MB, Bensard DD, Brew EC, et al. Transient ischemia preconditions against subsequent cardiac ischemia reperfusion injury by an alpha-1 adrenergic mechanism. Circ Res 1993;73:656-70.

3. Mitchell MB, Meng X, Parker CG, Brown JM, Harken AH, Banerjee A. Preconditioning of isolated rat heart is mediated by protein kinase C. Circ Res 1995;76:73-81.

4. Brew EB, Mitchell MB, Rehring TF, Gamboni-Robertson F, McIntyre RC, Harken AH, Banerjee A. The role of bradykinin in cardiac functional protection after global ischemiareperfusion in the rat heart. Am J Physiol 1995;269:H1370-8.

5. Kloner RA, Shook T. Previous angina alters in-hospital outcome in TIMI-4: a clinical correlate to preconditioning. Circulation 1995;91:37-45.

6. Kida M, Fujiwara H, Ishida M, Kawai C, Ohura M, Miura I, et al. Ischemic preconditioning preserves creatine phosphate and intracellular pH. Circulation 1991;84:2495-503.

7. Meldrum DR, Mitchell MB, Banerjee A, Harken AH. Cardiac preconditioning: induction of endogenous tolerance to ischemia-reperfusion injury. Arch Surg 1993;128:1208-11.

8. Meldrum DR, Cleveland JC, Sheridan BC, Rowland RT, Banerjee A, Harken AH. Cardiac surgical implications of calcium dyshomeostasis in the heart. Ann Thorac Surg 1996;61:1273-80.

9. Steenbergen C, Perlman ME, London RE, Murphy E. Mechanism of preconditioning: ionic alterations. Circ Res 1993;72: 112-25.

10. Thornton J, Striplin S, Liu GS, Swafford A, Stanley AW, Van Winkle DM, et al. Inhibition of protein synthesis does not block myocardial protection afforded by preconditioning. Am J Physiol 1990;259(6 Pt 2):H1822-5.

11. Tsuchida A, Liu Y, Liu GS, Cohen MV, Downey JM. $\alpha_{1}$-Adrenergic agonists precondition rabbit ischemic myocardium independent of adenosine by direct activation of protein kinase C. Circ Res 1994;75:576-85.

12. $\mathrm{Li} \mathrm{Y}$, Kloner RA. Does protein kinase $\mathrm{C}$ play a role in ischemic preconditioning in rat hearts? Am J Physiol 1995; 268:H1426-31.

13. Ytrehus K, Liu Y, Downey JM. Preconditioning protects ischemic rabbit heart by protein kinase $\mathrm{C}$ activation. Am J Physiol 1994;266:H1145-52.

14. Speechly-Dick ME, Mocanu MM, Yellon DM. Protein kinase $C$. Its role in ischemic preconditioning in the rat. Circ Res 1994;75:586-90.

15. Goto M, Liu Y, Yang X, Ardell JL, Cohen MV, Downey JM. Role of bradykinin in protection of ischemic preconditioning in rabbit hearts. Circ Res 1995;77:611-21.

16. Nishizuka Y. Intracellular signaling by hydrolysis of phospholipids and activation of protein kinase C. Science 1992;258: 607-13.

17. Brown JM, Grosso M, Terada L, Whitman GJ, Banerjee A, White $\mathrm{CW}$, et al. Endotoxin pretreatment increases endogenous myocardial catalase activity and decreases ischemiareperfusion injury of isolated rat hearts. Proc Natl Acad Sci U S A 1989;86:2516-20.

18. Brown JM, White CW, Terada LS, Grosso MA, Shanley PF, Mulvin DW, et al. Interleukin 1 pretreatment decreases ischemia/reperfusion injury. Proc Nati Acad Sci U S A 1990;87:5026-30.

19. Banerjee A, Grosso MA, Brown JM, Rogers K, Whitman GJ. Oxygen metabolite effects on creatine kinase and cardiac energetics after reperfusion. Am J Physiol 1991;261:H590-7.

20. Ashraf M, Suleiman J, Ahmad M. Calcium preconditioning elicits a unique protection against the calcium paradox injury in rat heart: role of adenosine. Circ Res 1994;74:360-7.

21. Chaudry I. Cellular mechanisms in shock and ischemia and their correction. Am J Physiol 1983;245:R117-34.

22. Limas C, Olivari MT, Goldenberg T, Benditt D, Simon A. Calcium uptake by cardiac sarcoendoplasmic reticulum in human dilated cardiomyopathy. Cardiovasc Res 1987;21: 601-5.

23. Sayeed MM. Alterations in cellular calcium regulation in the liver in endotoxic shock. Am J Physiol 1986;250:R884-91.

24. Meldrum DR, Ayala A, Chaudry IH. Mechanism of diltiazem's immunoprotective effects following hemorrhage and resuscitation. Am J Physiol 1993;265:C412-21.

25. Meldrum DR, Ayala A, Perrin MM, Ertel W, Chaudry IH. Diltiazem restores IL-2, IL-3, IL-6, and IFN- $\gamma$ synthesis and decreases host susceptibility to sepsis following hemorrhage. J Surg Res 1991;51:158-64.

26. Wang P, Ba Z, Meldrum DR, Chaudry IH. Diltiazem restores cardiac output and improves renal function following hemorrhage and resuscitation. Am J Physiol 1992;266: H1435-40.

27. Shen A, Jennings R. Myocardial calcium and magnesium in acute ischemic injury. Am J Pathol 1972;67:417-40.

28. Steenbergen C, Murphy E, Watts JA, London RE. Correlation between cytosolic free calcium, contracture, ATP, and irreversible ischemic injury in perfused rat heart. Circ Res 1990;66:135-46.

29. Steenbergen C, Fralix T, Murphy E. Role of increased cytosolic calcium concentration in myocardial ischemic injury. Basic Res Cardiol 1993;88:456-70.

30. Thornton JD, Liu GS, Olsson RA, Downey JM. Intravenous pretreatment with $\mathrm{A}_{1}$ selective adenosine analogues protects the heart against infarction. Circulation 1992;85:659-65.

31. Asimakis GK, Conti VR. Preconditioning with dobutamine in the isolated rat heart. Life Sci 1995;57:177-87.

32. Minneman KP. Alpha 1-adrenergic receptor subtypes, inositol triphosphates and sources of cell $\mathrm{Ca} 2+$. Pharmacol Rev 1988;40:87-119. 